\title{
Molecular detection of Babesia rossi and Hepatozoon sp. in African wild dogs (Lycaon pictus) in South Africa
}

\author{
Paul Tshepo Matjila ${ }^{\mathrm{a}, *}$, Andrew L. Leisewitz ${ }^{\mathrm{a}}$, Frans Jongejan ${ }^{\mathrm{a}, \mathrm{b}}$, \\ Henk J. Bertschinger ${ }^{c}$, Barend L. Penzhorn ${ }^{\mathrm{a}}$ \\ ${ }^{a}$ Department of Veterinary Tropical Diseases, Faculty of Veterinary Science, \\ University of Pretoria, Private Bag x04, 0110 Onderstepoort, South Africa \\ ${ }^{\mathrm{b}}$ Utrecht Centre for Tick-borne Diseases (UCTD), Department of Infectious Diseases and Immunology, \\ Faculty of Veterinary Medicine, Utrecht University, Yalelaan 1, 3584 CL, Utrecht, The Netherlands \\ ${ }^{\mathrm{c}}$ Department of Production Animal Studies, Faculty of Veterinary Science, University of Pretoria, \\ Private Bag x04, 0110 Onderstepoort, South Africa
}

Received 21 April 2008; received in revised form 3 July 2008; accepted 15 July 2008

\begin{abstract}
Blood specimens from wild dogs $(n=301)$ were obtained from De Wildt Cheetah and Wildlife Centre (Pretoria) and five game reserves (4 in the North-West Province and 1 in Limpopo Province), South Africa. Specimens were screened for Babesia, Theileria, Hepatozoon and EhrlichialAnaplasma species using PCR and Reverse Line Blot (RLB) assays. Positive results were obtained in 18 $(6 \%)$ wild dogs. Sixteen specimens were found positive for Babesia rossi and two dogs were Hepatozoon sp. positive. It appears that these tick-borne pathogens are not widely distributed in wild dog populations.
\end{abstract}

(C) 2008 Elsevier B.V. All rights reserved.

Keywords: African wild dog; Babesia rossi; Hepatozoon; Lycaon pictus; RLB; South Africa

\section{Introduction}

Babesia rossi, originally described from a side-striped jackal (Canis adustos) in East Africa (Nuttall, 1910), is the causative agent of canine babesiosis, a major clinical problem in domestic dogs in South Africa (Collett, 2000). Being a vector-specific parasite transmitted by Haemaphysalis elliptica (previously lumped with Haemaphysalis leachi; Apanaskevich et al., 2007), B. rossi occurs only in sub-Saharan Africa (Lewis et al., 1996).

The large piroplasms causing babesiosis in domestic dogs were generally referred to as "Babesia canis" until Uilenberg et al. (1989) drew attention to the fact

\footnotetext{
* Corresponding author. Tel.: +27 125298424; fax: +27 125298312.

E-mail address: tshepo.matjila@up.ac.za (P.T. Matjila).
}

that there were three separate, vector-specific taxa involved: B. canis (senso stricto), transmitted by Dermacentor reticulatus; Babesia vogeli, transmitted by Rhipicephalus sanguineus; and B. rossi. Although $B$. rossi is a common infection in dogs in South Africa, $B$. vogeli also occurs (Matjila et al., 2004).

There are pre-1989 accounts in the literature of "Babesia canis" (senso lato) from domestic dogs being transmitted naturally and artificially to African wild dogs (Lycaon pictus) and black-backed jackals (Canis mesomelas) in South Africa, with no untoward effects (Neitz, 1965; Neitz and Steyn, 1947; Van Heerden, 1980).

Hepatozoon gametocytes are commonly found in blood smears of free-ranging carnivores such as lions (Panthera leo), leopards (Panthera pardus), cheetahs 
(Acinonyx jubatus), spotted hyaenas (Crocuta crocuta) and even large-spotted genet (Genetta tigrina) (Averbeck et al., 1990; Brocklesby and Vidler, 1963, 1965; Keep, 1970; McCully et al., 1975; Penzhorn et al., 1992). Except for one case, that of a newly introduced cheetah that carried a severe tick burden (Keep, 1970), these were incidental findings. A Hepatozoon was identified from swellings on the leg joints of a lion (Maddock et al., 1996). Hepatozoon-like parasites have even been described from the tissues of impalas (Aepyceros melampus) (Basson et al., 1967; Keep, 1970).

Hepatozoon gametocytes found on blood smears of African carnivores are often called $H$. canis, irrespective of the host, and various named species from other hosts species have been lumped under H. canis (Levine, 1988). It has also been suggested that "Microbesnoitia leoni", described from the tissues of a lion (Bwangamoi, 1989), is a junior synonym of $H$. canis (Dubey and Bwangamoi, 1994). Clear morphological differences of Hepatozoon gametocytes found in cheetahs and wild dogs, respectively, suggest that synonymising many African species with $H$. canis may be erroneous (Peirce et al., 1995).

We endeavoured to ascertain which of the three Babesia taxa, as well as other protozoa and rickettsias commonly found in domestic dogs, occurred naturally in wild dog populations in South Africa.

\section{Materials and methods}

\subsection{Collection of specimens}

Blood specimens $(n=301)$ were collected into EDTA Vacutainer ${ }^{\circledR}$ (Franklin Lakes, USA) tubes from the jugular vein of apparently healthy wild dogs (Lycaon pictus) from the following areas: De Wildt Cheetah and Wildlife Centre $(n=227)$; Pilanesberg National Park $(n=18)$; Letsile Game Reserve $(n=9)$; Marekele Game Reserve $(n=5)$ and Mafunyane Game Reserve $(n=5)$ in North-West Province, and Kapama Game Reserve $(n=37)$, in Limpopo Province, South Africa. Prior to blood collection, the dogs were immobilised by intramuscular administration of medetomidine (Domitor, Novartis) (total dose $80-90 \mu \mathrm{g} / \mathrm{kg}$ ) in combination with ketamine hydrochloride (Anaket-V, Centaur Labs) (total dose 20-25 mg) (Van Heerden et al., 2002). Blood specimens were refrigerated and sent to the Faculty of Veterinary Science, University of Pretoria.

\subsection{DNA extraction}

DNA was extracted from $200 \mu \mathrm{l}$ of each blood specimen. The QIAmp blood and tissue extraction kit
(Qiagen, Hilden, Germany) was used for DNA extractions, following the manufacturer's protocols.

\section{3. $P C R$}

The Babesia/Theileria/Hepatozoon PCR was performed with primers RLB-F2 (5'-GAC ACA GGG AGG TAG TGA CAA G-3') and RLB-R2 (biotin-5'-CTA AGA ATT TCA CCT CTG ACA GT- $3^{\prime}$ ) amplifying a fragment of $460-540 \mathrm{bp}$ from the 18S rRNA gene spanning the V4 region (Gubbels et al., 1999; Matjila et al., 2004). The EhrlichialAnaplasma PCR was performed with the forward primer Ehr-F (5'-GGA ATT CAG AGT TGG ATC MTG GYT CAG-3') and Ehr-R (5'-Biotin-CGG GAT CCC GAG TTT GCC GGG ACT TYT TCT-3') amplifying a fragment of 460 $520 \mathrm{bp}$ from the $\mathrm{V} 1$ hypervariable region of the $16 \mathrm{~S}$ SSU rRNA gene (Bekker et al., 2002; Nijhof et al., 2005). The conditions for the PCR included an initial step of $3 \mathrm{~min}$ at $42{ }^{\circ} \mathrm{C}, 10 \mathrm{~min}$ at $94{ }^{\circ} \mathrm{C}, 10$ cycles of $94{ }^{\circ} \mathrm{C}(20 \mathrm{~s})-67{ }^{\circ} \mathrm{C}(30 \mathrm{~s})-72{ }^{\circ} \mathrm{C}(30 \mathrm{~s})$, with lowering of annealing step after every second cycle with $2{ }^{\circ} \mathrm{C}$ (touchdown PCR). The reaction was then followed by 40 cycles of denaturation at $94{ }^{\circ} \mathrm{C}$ for $30 \mathrm{~s}$, annealing at $57{ }^{\circ} \mathrm{C}$ for $30 \mathrm{~s}$ and extension at $72{ }^{\circ} \mathrm{C}$ for $30 \mathrm{~s}$.

\subsection{Reverse line blot hybridisation}

RLB was subsequently conducted on amplified products (Babesia, Theileria, Hepatozoon, Anaplasma and Ehrlichia) as previously described (Matjila et al., 2004). The list of probes and their sequences used for detecting pathogen DNA are listed in Table 1.

\section{Results}

Eighteen $(6.0 \%)$ of the 301 specimens, all originating from De Wildt Cheetah and Wildlife Centre, were positive: $16(5.3 \%)$ for $B$. rossi and $2(0.7 \%)$ for Hepatozoon sp.

\section{Discussion}

Previous studies have reported on a fatal case of acute babesiosis in a juvenile African wild dog in the Johannesburg Zoologial Gardens (Colly and Nesbit, 1992). On microscopic examination, trophozoites presumed to be "Babesia canis" were observed in 2/ $29(6.9 \%)$ of blood smears from wild dogs in the Kruger National Park (Van Heerden et al., 1995). Additionally, a single piroplasm, possibly Babesia sp., was seen on a blood smear from 1/16 wild dogs in Serengeti National 
Table 1

List of organisms and their corresponding probe sequences used to detect pathogen DNA

\begin{tabular}{|c|c|}
\hline Anaplasma centrale & TCG AAC GGA CCA TAC GC \\
\hline Anaplasma marginale & GAC CGT ATA CGC AGC TTG \\
\hline Anaplasma ovis & ACC GTA CGC GCA GCT TG \\
\hline Anaplasma phagocytophilum 1 & TTG CTA TAA AGA ATA ATT AGT GG \\
\hline Anaplasma phagocytophilum 3 & TTG CTA TGA AGA ATA ATT AGT GG \\
\hline Anaplasma phagocytophilum 5 & TTG CTA TAA AGA ATA GTT AGT GG \\
\hline Anaplasma phagocytophilum 7 & TTG CTA TAG AGA ATA GTT AGT GG \\
\hline Ehrlichia/Anaplasma catch-all & GGG GGA AAG ATT TAT CGC TA \\
\hline Ehrlichia canis/Ehrlichia ovina & TCT GGC TAT AGG AAA TTG TTA \\
\hline Ehrlichia chaffeensis & ACC TTT TGG TTA TAA ATA ATT GTT \\
\hline Ehrlichia ruminantium & AGT ATC TGT TAG TGG CAG \\
\hline Ehrlichia sp. (Omatjenne) & CGG ATT TTT ATC ATA GCT TGC \\
\hline Hepatozoon catch-all & GCT TTG TAA TTG GAA TGA TAG A \\
\hline Theileria/Babesia catch-all & TAA TGG TTA ATA GGA RCR GTT G \\
\hline Theileria annae & CCG AAC GTA ATT TTA TTG ATT TG \\
\hline Theileria annulata & CCT CTG GGG TCT GTG CA \\
\hline Theileria bicornis & GCG TTG TGG CTT TTT TCT G \\
\hline Theileria buffeli & GGC TTA TTT CGG WTT GAT TTT \\
\hline Theileria catch-all & ATT AGA GTG CTC AAA GCA GGC \\
\hline Theileria equi & TTC GTT GAC TGC GYT TGG \\
\hline Theileria parva & GGA CGG AGT TCG CTT TG \\
\hline Theileria sp. (buffalo) & CAG ACG GAG TTT ACT TTG T \\
\hline Theileria sp. (duiker) & CAT TTT GGT TAT TGC ATT GTG G \\
\hline Theileria sp. (kudu) & CTG CAT TGT TTC TTT CCT TTG \\
\hline Theileria sp. (sable) & GCT GCA TTG CCT TTT CTC C \\
\hline Theileria taurotragi & TCT TGG CAC GTG GCT TTT \\
\hline Theileria velifera & CCT ATT CTC CTT TAC GAG T \\
\hline Babesia bigemina & CGT TTT TTC CCT TTT GTT GG \\
\hline Babesia bovis & CAG GTT TCG CCT GTA TAA TTG AG \\
\hline Babesia caballi & GTG TTT ATC GCA GAC TTT TGT \\
\hline Babesia canis & TGC GTT GAC CGT TTG AC \\
\hline Babesia canis 2 & TGG TTG GTT ATT TCG TTT TCG \\
\hline Babesia catch-all 1 & ATT AGA GTG TTT CAA GCA GAC \\
\hline Babesia catch-all 2 & ACT AGA GTG TTT CAA ACA GGC \\
\hline Babesia felis & TTA TGC GTT TTC CGA CTG GC \\
\hline Babesia gibsoni Japan & TAC TTG CCT TGT CTG GTT T \\
\hline Babesia gibsoni USA & CAT CCC TCT GGT TAA TTT G \\
\hline Babesia microti & GRC TTG GCA TCW TCT GGA \\
\hline Babesia ovis & TGC GCG CGG CCT TTG CGT T \\
\hline Babesia rossi & CGG TTT GTT GCC TTT GTG \\
\hline Babesia vogeli & AGC GTG TTC GAG TTT GCC \\
\hline
\end{tabular}

Park, Tanzania (Peirce et al., 1995). This study is the first report of molecular detection and characterization of Babesia parasites in African wild dogs. B. rossi appears to be the species infecting wild dogs and this study confirms previous studies that prevalence is fairly low in wild dog populations. Clinical babesiosis has not been reported from African wild dogs in any of the populations sampled. B. rossi infections cause a severe to fatal disease in domestic dogs (Jacobson, 2006). It is still not clear whether there is any clinical significance of $B$. rossi infections in wild dogs as there is in domestic dogs. The implication is that $B$. rossi might be a natural parasite of wild dogs.
Haemaphysalis elliptica, the only known vector of $B$. rossi, has been recorded from domestic and wild dogs (Horak, 1995; Van Heerden, 1986; Van Heerden et al., 1995). In as far as we can ascertain, there is no physical contact between domestic and wild dogs in South Africa. The fact that wild dogs are endangered and a protected species, makes them extremely valuable. Proper care is taken in avoiding contact between domestic and wild dogs. The only known case of a fatal acute babesiosis in a wild dog juvenile was, however, reported to have been a vaccine related entity, since the acute severe disease occurred 12 days after vaccination. Furthermore, the authors stated that there might have 
been a possible tick transmission since there was a potential for an excessive tick burden in the wild dog enclosure, because of dog-walking activities along the zoo perimeter (Colly and Nesbit, 1992). The risk implications of transmitting parasites from one dog species to the other, however, remain low.

Previous studies have found Hepatozoon gametocytes in 26/29 (89.7\%) of blood smears from wild dogs in the Kruger National Park (Van Heerden et al., 1995). Peirce et al. (1995) found Hepatozoon gametocytes in 13/16 $(81.5 \%)$ wild dogs in the Serengeti. Our study uses molecular techniques to confirm Hepatozoon infections in wild dogs. The low prevalence of Hepatozoon sp. reported here contrasts with these findings. The low prevalence reported here may be as a result of strict tickcontrol practised in the two captive populations (De Wildt and Kapama), where most of our specimens originated. These populations are under strict veterinary care and it would appear that strict tick-control measures can effectively reduce Hepatozoon burdens in captive wild dog populations.

Based on our current results, it would appear that these tick-borne pathogens are not widely distributed in wild dog populations. Furthermore, since we could not associate parasite infections to clinical disease, we are of the opinion that clinical importance of Babesia and/ or Hepatozoon infections in wild dogs is insignificant.

\section{Acknowledgements}

We would like to thank the Genetics Laboratory of the Faculty of Veterinary Science for providing some of the wild dog samples. This work forms part of an ongoing $\mathrm{PhD}$ research project funded by the Thuthuka NRF fund and an institutional collaboration agreement (95401) between the Institute of Tropical Medicine, Antwerp, Belgium, and the Department of Veterinary Tropical Diseases, University of Pretoria. This project (V042/05) was approved by the Animal Use and Care Committee of the University of Pretoria and the Research Committee of the Faculty of Veterinary Science.

\section{References}

Apanaskevich, D.A., Horak, I.G., Camica, J.-L., 2007. Redescription of Haemaphysalis (Rhipistoma) elliptica (Koch, 1844), an old taxon of the Haemaphysalis (Rhipistoma) leachi group from East and Southern Africa, and of Haemaphysalis (Rhipistoma) leachi (Audouin, 1826) (Ixodida, Ixodidae). Onderstepoort J. Vet. Res. 74, 181-208.

Averbeck, G.A., Bjork, K.E., Packer, C., Herbst, L., 1990. Prevalence of hematozoans in lions (Panthera leo) and cheetah (Acinonyx jubatus) in Serengeti National Park and Ngorongoro Crater. J. Wildl. Dis. 26, 392-394.

Basson, P.A., McCully, R.M., Bigalke, R.D., van Niekerk, J.W., 1967. Observations of a Hepatozoon-like parasite in the impala. J. S. Afr. Vet. Med. Ass. 38, 12-14.

Bekker, C.P.J., de Vos, S., Taoufik, A., Sparagano, O.A.E., Jongejan, F., 2002. Simultaneous detection of Anaplasma and Ehrlichia species in ruminants and detection of Ehrlichia ruminantium in Amblyomma variegatum ticks by reverse line blot hybridization. Vet. Microbiol. 89, 223-238.

Brocklesby, D.W., Vidler, B.O., 1963. Some new host records for Hepatozoon species in Kenya. Vet. Rec. 75, 1265.

Brocklesby, D.W., Vidler, B.O., 1965. Some parasites of East African wild animals. E. Afr. Wildl. J. 3, 120-122.

Bwangamoi, O., 1989. Microbesnoitia leoni, genus et species novo, a protozoan parasite of the lion, Felis leo, in Kenya. Bull. Anim. Health Prod. Afr. (Special issue) 173-176.

Collett, M.G., 2000. Survey of canine babesiosis in South Africa. J. S. Afr. Vet. Assoc. 71, 180-186.

Colly, L.P., Nesbit, J.W., 1992. Fatal acute babesiosis in a juvenile wild dog (Lycaon pictus). J. S. Afr. Vet. Assoc. 63, 36-38.

Dubey, J.P., Bwangamoi, O., 1994. Microbesnoitia leoni Bwangamoi, 1989, from the African lion (Panthera leo) redetermined as a junior synonym of Hepatozoon canis (James, 1905) Wenyon, 1926. J. Parasitol. 80, 333-334.

Gubbels, J.M., de Vos, A.P., Van der Weide, M., Viseras, J., Schouls, L.M., de Vries, E., Jongejan, F., 1999. Simultaneous detection of bovine Theileria and Babesia species by reverse line blot hybridization. J. Clin. Microbiol. 37, 17821789.

Horak, I.G., 1995. Ixodid ticks collected at the Faculty of Veterinary Science, Onderstepoort, from dogs diagnosed with Babesia canis infection. J. S. Afr. Vet. Assoc. 66, 170-171.

Jacobson, L.S., 2006. The South African form of severe and complicated canine babesiosis: clinical advances 1994-2004. Vet. Parasitol. 138, 126-139.

Keep, M.E., 1970. Short Veterinary Notes. No. 3. Hepatozoonosis of some wild animals in Zululand. Lammergeyer 12, 70-71.

Levine, N.D., 1988. The Protozoan Phylum Apicomplexan, vol. I. CRC Press, Bacon Raton.

Lewis, B.D., Penzhorn, B.L., Lopez-Rebollar, L.M., de Waal, D.T., 1996. Isolation of a South African vector-specific strain of Babesia canis. Vet. Parasitol. 63, 9-16.

Maddock, A., Anderson, A., Carlisle, F., Galli, N., James, A., Verster, A., Whitfield, W., 1996. Changes in lion numbers in HluhluweUmfolozi Park. Lammergeyer 44, 6-18.

Matjila, P.T., Penzhorn, B.L., Bekker, C.P., Nijhof, A.M., Jongejan, F., 2004. Confirmation of occurrence of Babesia canis vogeli in domestic dogs in South Africa. Vet. Parasitol. 122, 119-125.

McCully, R.M., Basson, P.A., Bigalke, R.D., de Vos, V., Young, E., 1975. Observations on naturally acquired hepatozoonosis of wild carnivores and dogs in the Republic of South Africa. Onderstepoort J. Vet. Res. 42, 117-134.

Neitz, W.O., 1965. A checklist and hostlist of the zoonoses occurring in mammals and birds in South Africa. Onderstepoort J. Vet. Res. 32, 189-374.

Neitz, W.O., Steyn, H.P., 1947. The transmission of Babesia canis (Piana and Galli-Valerio, 1895) to the black-backed jackal [Thos mesomelas (Schreber)], with a discussion on the classification of the piroplasms of the Canidae. J. S. Afr. Vet. Med. Ass. 18, 1-12.

Nijhof, A.M., Pillay, V., Steyl, J., Prozesky, L., Stoltsz, W.H., Lawrence, J.A., Penzhorn, B.L., Jongejan, F., 2005. Molecular char- 
acterization of Theileria species associated with mortality in four species of African antelopes. J. Clin. Microbiol. 43, 5907-5911.

Nuttall, G.F.H., 1910. On haematozoa occurring in wild animals in Africa. 1. Piroplasma rossi N. Sp. and Haemogregarina canis adusti N. Sp. found in the jackal. Parasitology 3, 108-116.

Peirce, M.A., Laurenson, M.K., Gascoyne, S.C., 1995. Hepatozoonosis in cheetahs and wild dogs in the Serengeti ecosystem. Afr. J. Ecol. 33, 273-275.

Penzhorn, B.L., de Waal, D.T., López-Rebollar, L.M., 1992. Identification of some haematozoa from lions. J. S. Afr. Vet. Assoc. 63, 96.

Uilenberg, G., Franssen, F.F., Perie, N.M., Spanjer, A.A., 1989. Three groups of Babesia canis distinguished and a proposal for nomenclature. Vet. Q. 11, 33-40.
Van Heerden, J., 1980. The transmission of Babesia canis to the wild dog Lycaon pictus (Temminck) and black-backed jackal (Canis mesomelas) Schreber. J. S. Afr. Vet. Assoc. 51, 119-120.

Van Heerden, J., 1986. Disease and mortality of captive hunting dogs Lycaon pictus. S. Afr. J. Wildl. Res. 16, 7-11.

Van Heerden, J., Bingham, J., van Vuuren, M., Burroughs, R.E., Stylianides, E., 2002. Clinical and serological response of wild dogs (Lycaon pictus) to vaccination against canine distemper, canine parvovirus infection and rabies. J. S. Afr. Vet. Assoc. 73, 8-12.

Van Heerden, H.J., Mills, M.G., van Vuuren, M.J., Kelly, P.J., Dreyer, M.J., 1995. An investigation into the health status and diseases of wild dogs (Lycaon pictus) in the Kruger National Park. J. S. Afr. Vet. Assoc. 66, 18-27. 